\title{
Uma Prática Pedagógica Comum: Escola isolada e escola privada de Arapiraca na década de 1950
}

\author{
Maria Aparecida de Farias* \\ Universidade Estadual de Alagoas
}

\begin{abstract}
Resumo
Este trabalho apresenta uma análise da prática pedagógica desenvolvida numa escola isolada e na primeira escola privada de Arapiraca na década de 1950 quando em diversas cidades brasileiras já eram percebidas as reformas no campo pedagógico. A intenção é compreender a trajetória da história da educação na cidade de Arapiraca/Alagoas, enfatizando a ação pedagógica desenvolvida de forma tradicional no processo de escolarização desta cidade, principalmente pela professora D.Linda e pelo professor Pedro de França Reis, influenciando de forma positiva a formação dessa comunidade como veremos no decorrer desse trabalho. Esta análise está fundamentada nas concepções weberianas que tratam do patrimonialismo brasileiro e sua relação com a educação; são abordadas também, formulações de Verçosa (2001) que rastreia os reflexos desse patrimonialismo em Alagoas. Outros estudiosos foram fundamentais para sustentação de nossa análise, a exemplo de Guedes (1999) e Macedo (1992) A História Oral foi utilizada como elemento indispensável na elaboração desse trabalho. Dessa forma percebemos que o processo de escolarização desenvolvido em Arapiraca na década de 1950, com uma prática tradicional, consoante com o que ocorria ainda em diversas partes do país, contribuiu, de forma positiva para o desenvolvimento social do povo arapiraquense, conforme depoimentos que ficarão explícitos nesse trabalho.
\end{abstract}

Palavras-chave: prática pedagógica, educação, formação

\begin{abstract}
This work presents developed a practical analysis of the pedagogical one in an isolated school and in the first private school of Arapiraca in the decade of 1950 when in diverse Brazilian cities already the reforms in the pedagogical field were perceived. The intention is to understand the trajectory of the history of the education in the city of Arapiraca/Alagoas, being emphasized the developed pedagogical action of traditional form in the process of scholarization of this city, mainly for Pretty teacher D. and the professor Peter of France Kings, influencing of positive form the formation of this community as we will see in elapsing of this work. This analysis is based on the weberians conceptions that deal with the Brazilian patrimonyalism and its relation with the education; they are boarded also, formularizations of Verçosa (2001) that it tracks the consequences of this patrimonyalism in Alagoas. Other scholars had been basic for sustentation of our analysis, the example of Guedes (1999) and Macedo (1992) Verbal History were used as indispensable element in the elaboration of this work. Of this form we perceive that the process of scholarization developed in Arapiraca in the decade of 1950, with traditional practical one, consonant with what he still occurred in diverse parts of the country, contributed, of positive form for the social development of the arapiraquense people, as depositions that will be explicit in this work.
\end{abstract}

Keywords: practical pedagogical, education, formation

\section{Introdução}

Para elaboração desse trabalho, foram tomados como objetos de estudo, uma escola isolada, a Escola da "D. Linda" como era conhecida a Escola Gabino Besouro e a primeira escola privada de Arapiraca. Para análise do fenômeno que nos propomos discutir, abordamos textos de Weber (2005) que favorecem a compreensão sobre a relação do Patrimonialismo com a

\footnotetext{
* Mestra em Educação Brasileira pelo Centro de Educação da Universidade Federal de Alagoas - UFAL, com pesquisa intitulada "O romper do silêncio: história e memória na trajetória da educação em Arapiraca, a partir de 1950", sob orientação do Prof. Dr. Élcio de Gusmão Verçosa.
} 
educação em Arapiraca, quando "a dominação patriarcal (do pai de família, do chefe da parentela ou do 'soberano') não é senão o tipo mais puro da dominação tradicional" (WEBER, 2001, parte 2, p. 353). Para o autor o tipo mais puro de dominação tradicional é o patriarcal em que o senhor é "santificado"e respeitado pelos súditos que the conferem fidelidade. Por outro lado, considera esse tipo de dominação como legítima por sempre ter existido e ser aceita pela sociedade.

Portanto percebemos que a concepção de dominação weberiana aponta para uma visão em que essa legitimidade, apesar de centrada na tradição que não pode ser violada, é, de uma forma ou de outra, suplantada pela figura do patriarca cuja sabedoria lhe é atribuída. Este, tendo em vista a fidelidade que Ihe é prestada passa a usar de poderes inquestionáveis pelos demais membros do grupo., organiza o poder político e escolhe as pessoas que deverão ocupar os cargos administrativos através de critérios estabelecidos pela relação de confiança, de amizade e interesses pessoais. Essas concepções vão contribuir para esta análise, numa perspectiva neopatrimonial, do Brasil, de Alagoas e consequentemente de Arapiraca, principalmente na década de 1950.

As relações patrimonialistas fortaleceram-se na sociedade brasileira com a chegada da Corte Portuguesa, que se estabeleceu no Brasil, comprometendo a história das Instituições com as concepções organicistas da vida social e afirmando a racionalidade burocrática em detrimento da racional e legal. Dessa forma, constituiu-se a estrutura patrimonial no Brasil e conseqüentemente em Alagoas e Arapiraca, caracterizada pelo patriarcalismo, compadrio, familismo e, sobretudo, pelo coronelismo que se manifesta numa troca de favores entre o governo do Estado e o chefe político local. Como mediador na garantia dos interesses do povo, "o coronel utiliza seus poderes públicos para fins particulares, mistura, não raro, a organização estatal e seu erário com os bens próprios" (FAORO, 2000, v.1, p. 637).

Procuramos nesta discussão, apoiados numa bibliografia local e nos depoimentos de pessoas com mais de setenta anos com capacidade física e mental de fornecer informações precisas, enfatizar como o processo de escolarização em Arapiraca, no período analisado, desenvolveu-se de forma tradicional dentro de uma ética paternalista cristã propiciando um ensino que 
garantiu, de certo modo, a formação daquele povo chegando a motivar alguns jovens a ingressarem na vida religiosa, optando, as moças, principalmente, pela ordem franciscana no Convento de Salvador. "As peculiaridades mentais e espirituais adquiridas no meio ambiente, especial do tipo de educação favorecido pela atmosfera religiosa da família e do lar determinaram a escolha da ocupação e por isso da carreira" (WEBER, 2005, p.39). A Igreja foi, portanto, a Instituição que teve papel mais relevante na educação do povo arapiraquense, através da ação de padres oriundos das famílias tradicionais daquele município a exemplo do Padre Francisco Xavier Macedo e outros.

\section{Desenvolvimento}

A história oficial de Arapiraca, principalmente nas formulações de Guedes (1999) apregoa que seus povoadores eram todos alfabetizados, sem levar em consideração os filhos de ex-escravos e de trabalhadores que, envolvidos no cultivo da mandioca e mais tarde do fumo, ficaram excluídos do acesso ao ensino elementar. Arapiraca tem como marco inicial de seu povoamento o ano de 1848 sendo seu fundador, Manoel André, casado com a filha de Manoel da Silva Valente, um ex-soldado do exército português que aqui chegara, em companhia da família real, quando esta se transferiu para o Brasil. Este, atraído pela imensidão das terras brasileiras, abandonou a vida militar e empenhou-se no desbravamento do sertão estabelecendo-se com toda a sua família em Cacimbinhas, no semi-árido alagoano.

Manoel André fora recomendado por seu sogro a buscar terras propícias ao plantio da mandioca para a fabricação da farinha, cuja procura aumentara significativamente no período imperial. Abandonando o sertão alagoano, seguiu para o agreste e alcançando as terras onde mais tarde ergueu-se o povoado de Arapiraca, abrigou-se à sombra de uma frondosa árvore, denominada "arapiraca"1, próxima ao Riacho Seco, cujas águas constituíram-se no elemento fundamental para o início do povoamento daquela localidade. Nas palavras de Guedes (1999) o crescimento desse povoado torna-se notório muito rápido, logo após dez anos da construção da primeira casa de taipa que pertenceu a Manoel André.

\footnotetext{
1 "Arapiraca" é uma árvore, a palavra de origem indígena significa "ramo que arara visita". Cientificamente, árvore da família das Leguminosas Minosáceas - Piptadênia, espécie de angico branco muito comum no agreste e no sertão.
} 
Com a morte de Manoel da Silva Valente (1875), seus herdeiros, que até então permaneciam em Cacimbinhas, procuram ocupar suas terras, que constituíam o novo povoado de Arapiraca. Os herdeiros de Valente se distribuíram em diversos sítios que circundavam o "quadro"2 do povoado e desta forma as famílias foram se multiplicando, através de casamentos entre parentes construindo-se numerosos núcleos familiares.

O entrelaçamento entre as famílias vai permitir o controle de enormes extensões de terras, formando assim o 'clã parental' que se vai desenvolvendo e ampliando prestígio por todo território, dando a esses grupos familiares dispostos em cada região, o poder de decidir politicamente, de acordo com os seus interesses particulares e convenientes de seus grupos (ALMEIDA, 1999, p. 35-36).

Dessa forma, surgiram diversos sítios: Mocó, a Serra dos Ferreiras, Lagoa de Dentro, Baixa Grande, o sítio Fernandes e outros de modo que cada sítio tinha seu chefe encarregado de tomar as decisões políticas e econômicas capazes de promover o desenvolvimento do povo daquela localidade.

O poder atribuído a esses chefes aliados ao líder local que residia no "quadro" do povoado advinha da relação com as autoridades de S. João de Anadia e mais tarde de Limoeiro de Anadia, a que pertencia Arapiraca. Entre esses poderes constituídos estava a prática educacional "centrada no reconhecimento do pobre, de sua condição e do rico, de sua relação de cooperação, de ajuda..." (HUNT; SHERMAN, 1994, p. 16). O processo de escolarização de Arapiraca durante muito tempo ficou á mercê dos grandes proprietários e da Igreja que se achava comprometida com os conteúdos a serem desenvolvidos; alguns padres chegaram a ocupar cargo de Inspetor de Ensino.

Para ser professor nos fins do Império não bastava saber ler e escrever, mas, precisamente deveria dominar os fundamentos cristãos, era o predomínio dos "rotulados professores e na quase totalidade ignorantíssimos" (COSTA, 2001, p. 43). No caso de Arapiraca, aqueles que preenchessem tais requisitos eram solicitados para desenvolver o ensino nas residências, ou melhor, nos diversos sítios atendendo a determinadas pessoas, no caso, as mais

\footnotetext{
20 desmatamento feito nas proximidades da frondosa arapiraca onde Manoel André plantou sua roça e construiu sua casa, tinha a dimensão de um quadro por isso durante muito tempo o povoado ficou conhecido como Quadro de Arapiraca (GUEDES, 1999, p. 27).
} 
favorecidas, porque os filhos dos trabalhadores eram encarregados da produção da farinha e depois do cultivo do fumo. Percebemos que a maioria da população estava impossibilitada de participar do processo de escolarização e que esta visão de desenvolvimento educacional era consoante com a visão propagada comumente no Brasil em que o processo educativo se desenvolve de forma muito lenta mesmo havendo bruscas reformas em algumas regiões. O princípio da gratuidade da instrução pública firmado na primeira constituição brasileira, não fora cumprido; o ato adicional transferira para as províncias a responsabilidade da instrução pública e as escolas de primeiras letras orientavam que os professores deveriam ensinar, sobretudo, os princípios da moral cristã, a ler, escrever e contar. Isto significa que a educação elementar não era de interesse da elite, que defendia como prioridade, a criação de Escolas Superiores para preparar profissionais e políticos capazes de garantir a ordem e preservar o regime vigente.

Ramos (2001), explica a situação de Alagoas no início do Período Republicano, demonstrando que a instrução primária era desenvolvida sem nenhuma fiscalização e sem instrumentos adequados. Percebemos determinado avanço da instrução pública, mas, apenas no ensino secundário destinado às camadas mais abastadas, ficando o ensino primário no verdadeiro abandono, o que vai se fortalecer quando o governo provincial, em acordo com a Assembléia Legislativa da Província, fez provimento de cadeiras de professores primários a pessoas que soubessem apenas ler, escrever, dominassem as quatro operações fundamentais da aritmética e fossem versadas na doutrina cristã - católica.

Esse modelo caracteriza muito bem a forma como se desenvolvia o ensino no então povoado de Arapiraca, lá para os fins do Período Imperial e início do Período Republicano, quando a sua população ganhava outra característica com a entrada de novos povos vindos de outros municípios e de outros Estados. Alguns, atraídos pelo desenvolvimento econômico daquela região e outros à busca de refúgio para defender seus filhos da incorporação dos Voluntários da Pátria, ou seja, muitos fugiam do recrutamento da guerra do Paraguai ou buscavam sua sobrevivência, o que se tornara muito difícil com as conseqüências da guerra no Brasil. 
Com o advento da República, o Estado de Alagoas e consequentemente o Distrito de Arapiraca tomam novos rumos no âmbito político e econômico, mudando a trajetória educacional. "Alagoas entra no período republicano marcado pelo trabalho essencialmente rural com uma economia bastante atrasada do ponto de vista tecnológico, tendo o latifúndio como base primordial" (ALMEIDA, 1999, p.53). A exemplo de outros municípios alagoanos que conquistaram sua autonomia através do desenvolvimento econômico promovido pela cultura canavieira, em Arapiraca o plantio da mandioca constituiu os grupos dos novos ricos que passam a se destacar como protetores dos menos favorecidos. A liderança política atrelada ao desenvolvimento econômico de Arapiraca, centralizada na pessoa do Major Experidião Rodrigues, descendente de Manuel André, conseguiu que Arapiraca se desmembrasse de Limoeiro de Anadia, em 1924. A partir daí expandiu-se o processo educacional com a nomeação de uma nora e uma filha do então prefeito, Experidião Rodrigues, que foram nomeadas pelo governo estadual. Mais tarde surgem novas professoras indicadas pelas lideranças políticas para desenvolver o ensino nos diversos sítios. A exemplo dessas indicações destacou-se D. Linda, que graças ao desempenho econômico e alianças políticas do seu pai e do seu sogro com determinadas facções, conseguiu ser nomeada professora, primeiro do povoado Riachão e mais tarde no sítio Baixa Grande de Cima.

Esta professora desempenhou um papel relevante na cultura e na formação religiosa daquelas duas comunidades. Com sua metodologia tradicional ensinava a seus alunos a fazerem leituras de textos e escreverem, começando pelo alfabeto maiúsculo e minúsculo seguindo com as vogais e os algarismos arábicos e romanos para depois começar com sílabas, palavras, frases e paralelamente ensinava as quatro operações. "A memorização era utilizada como instrumento pedagógico, sendo muito ligada à oralidade da religião As escolas imitavam as cantilenas das ladainhas para memorizar 0 abecedário e a tabuada". (FARIAS, 2007, p38) A este paradigma associava-se o uso da palmatória que apesar de abolida por lei imperial foi muito usada na escolarização de Arapiraca nas primeiras décadas do período republicano por delegação das próprias famílias que consideravam o uso desse instrumento fundamental na disciplina dos alunos. 
Como todas as escolas isoladas daquela época, a escola de D. Linda, no povoado Riachão funcionava num salão cedido pelo sogro, conhecido como Manoel d’Aninha, considerado o chefe local, sendo por isso responsável pelos destinos da educação naquela localidade, onde era reconhecido como provedor. "O clientelismo político sempre foi e é antes de tudo, preferencialmente uma relação de favores políticos por benefícios econômicos não importa em que escala" (MARTINS, 1994, p.29). Não havia prédios específicos para o funcionamento de escolas. Quando se construía um salão com essa finalidade era nas terras dos grandes proprietários que se sentiam no direito de usá-los para outros fins. As escolas funcionavam em casas arranjadas às pressas sem nenhuma aparência de escola e professoras e alunos se encarregavam de trazer a mobília principalmente seus assentos como explica Ramos (2001). Caixotes eram utilizados para assento e as lições eram escritas apoiadas nas pernas do aluno que muitas vezes preferia ficar de joelhos fazendo a escrita no papel sobre o caixote.

A professora aqui mencionada, ainda na década de 1950 mudou sua residência para o sítio Baixa Grande de Cima onde continuou desenvolvendo sua prática pedagógica na escola isolada ali localizada contrariando às concepções de alguns estudiosos que contemplam ás novas professoras, qualificadas para o magistério. "As professoras novas ingressavam comumente nos grupos; as velhas ficavam nas escolas isoladas, desaprendendo o que sabiam, longe do mundo, ensinando coisas absurdas" (RAMOS, 2001, p.61). No referido sítio a professora D. Linda, que buscava sempre aprender mais através de informações que estivessem ao seu alcance, desenvolvia na sua própria residência, o ensino voltado para uma formação ética, moral e religiosa consoante com o processo educacional de Arapiraca e Alagoas e do Brasil. Não havia em Arapiraca nenhum grupo, apenas escolas isoladas que não tinham nome; eram conhecidas pelo nome da professora ou do proprietário. Isso significa que a escola criada no sítio Baixa Grande de Cima recebeu o nome de Escola Gabino Besouro, mas era conhecida por todos como a escola da D. Linda porque funcionava na sua residência. Isto foi comum em Arapiraca, até os anos 80 como foi possível detectar pelo Grupo de Pesquisa TEASA, Trajetória da Educação no Sertão e Agreste Alagoano, quando investigava decretos nos arquivos da Secretaria Municipal de Arapiraca. As escolas 
isoladas eram criadas com uma denominação mas ficavam conhecidas apenas pelo nome do sítio ou do professor, o que significa a invasão do público pelo privado.

$\mathrm{Na}$ casa da professora; os alunos ocupavam os bancos da sala, para preparar as lições que tinham de ser apresentadas á professora no fim do turno. Na hora de escrever estes passavam para a sala de jantar, a fim de aproveitar o apoio da mesa. Enfim todas as instalações da casa da professora eram utilizadas pelos alunos: banheiros, o pote que conservava a água potável para a família, até mesmo os dormitórios, pois quando estava chovendo muito, as crianças que moravam distante ficavam para dormir; os pais não se preocupavam porque sabiam que a professora acolhia. Enquanto os alunos usavam as instalações da professora, esta pedia aos mesmos que fizessem algum favor, como olhar a panela no fogo, pegar água no pote, etc. Além disso, os alunos que se destacavam na aprendizagem ajudavam nas atividades dos iniciantes, a exemplo do que ocorria no método mútuo, criado por Lancaster.

Lindinalva Eulália de Farias, conhecida como a professora "D.Linda", era muito religiosa e costumava visitar ás famílias, principalmente aquelas mais necessitadas, aproveitando o momento para evangelizar; nessas visitas rezava com todos da casa, inserindo o hábito da recitação do terço naquela comunidade, o que explica uma relação harmoniosa, entre professor, aluno e comunidade. $\mathrm{Na}$ escola, os estudantes aprendiam a rezar e eram encaminhados para a catequista da lgreja para serem levadas á primeira Eucaristia.

A professora ainda é lembrada como escritora e leitora das cartas que chegavam de São Paulo. Muitos moradores daquela localidade não sabiam ler e quando eram capazes de ler não sabiam escrever, portanto recorriam á professora que sempre aparecia com satisfação em atender ás solicitações. As cartas que chegavam eram escritas por semi-analfabetos e por isso ficava difícil de fazer a leitura, mas, a professora fazia questão de deixar claro o que estava dizendo a carta. Em seguida era a resposta que entrava em cena e a professora pegava papel e caneta e começava a ouvir o conteúdo que deveria compor a carta, procurando dar sentido ao que dizia o remetente e substituir as palavras que achava inconvenientes. Dessa forma podemos perceber que a prática pedagógica desenvolvida pela professora D.Linda, apesar de 
tradicional, foi de muita importância para a sociedade arapiraquense por onde estão espalhados os seus discípulos que costumam colocar na sua história de vida relatos como o de Bernadete Lima Ribeiro que comenta: "na escola da D. Linda eu aprendi a ler e escrever, mas também ela ensinava a rezar e respeitar os outros". Essa ex-aluna acrescenta em conversa informal, que nessa escola vivenciava-se os princípios morais e cristãos e que em poucos meses aprendeu a ler.

Outro professor que desenvolveu um ensino tradicional em Arapiraca, consoante com aquele desenvolvido por D. Linda, foi o professor Pedro de França Reis que ensinou no primeiro Grupo Escolar, Adriano Jorge, crido em 1943 e depois criou o Instituto São Luís, a primeira Instituição de Ensino particular naquela cidade. A semelhança entre esses dois educadores ocorre na ação pedagógica por eles desenvolvida e nos valores éticos, morais e cristãos defendidos pelos mesmos. No entanto as diferenças aparecem acentuadas: a formação da professora D. Linda era apenas de primeiras letras adquirida pela instrução elementar; sua sala de aula era multisseriada, funcionando na sua própria casa, sujeito a desconfortos. O professor Pedro Reis tinha qualificação para o magistério, lecionava no Grupo com salas confortáveis, seriadas e seus alunos eram oriundos da zona urbana; mais tarde criou uma escola particular onde só estudava quem tinha dinheiro, ou seja, atendia a uma classe elitizada.

O professor Pedro Reis, que foi impedido de assumir a direção do Adriano Jorge, por retaliação política, mas, que continuou sendo professor daquela instituição de ensino e que já tinha o hábito de ensinar particular nas cidades por onde passava, decidiu criar uma escola em Arapiraca, nascendo, assim, o Instituto São Luís, que merece destaque, por ser apontado pela história oficial como a primeira escola particular da cidade.

Relatos de pessoas que conviveram com o fundador do Instituto São Luís, colhidos em entrevistas, principalmente cedidas por Manoel Oliveira Barbosa, dão-nos conta de que Pedro Reis, como servidor público, percorreu vários municípios alagoanos exercendo a função de professor, por transferência ex-ofício, a exemplo de Maceió, Penedo, Santana do Ipanema, Porto Real de Colégio, Traipu, Delmiro Gouveia e, finalmente, Arapiraca, onde 
permaneceu até a morte, tendo sido sempre transferido por conta de perseguição decorrente das alternâncias das facções oligárquicas no poder estadual ou municipal com as quais não concordava politicamente.

O Instituto São Luís foi criado pelo Decreto Estadual de ํㅜㄴ.225, de 30 de dezembro de 1936, que autorizaria o funcionamento da escola. No entanto, - Professor Pedro Reis não poderia assumir a direção porque, sendo funcionário público, estava proibido de acumular, ainda que uma função de natureza privada, segundo a legislação em vigor. Manoel de Oliveira Barbosa, por ter sido aluno exemplar de Pedro Reis no Adriano Jorge, já estava incluído no quadro de mestres do Instituto quando foi indicado para assumir a direção com menos de dezessete anos. O Diretor de Educação do Estado de Alagoas, padre Luiz Medeiros Neto cedeu um certificado que garantia o registro do professor Manoel como diretor do Instituto, cujo teor segue transcrito:

\section{CERTIFICADO № 157}

Certifico que Manoel de Oliveira Barbosa se acha devidamente registrado na Diretoria de Educação, como professor particular da Instrução Primária da cidade de Arapiraca, município do mesmo nome, de acordo com o artigo 78, letras a, b e c do Decreto 2.225, de 03 Dezembro de1936, às folhas 84 do livro № I.

Sendo essa escola de cunho particular, significa dizer que, mais uma vez, a classe trabalhadora ficava de fora do processo de escolarização desenvolvido em Arapiraca. O ensino desenvolvido nessa escola, consoante com a educação dominante no país, era de cunho tradicional, no que pesem os movimentos de modernização pedagógica que, desde fins do Século XIX, já despontavam, aqui e ali, por todo o país. No Instituto São Luís o aluno deveria aprender por práticas rigorosas através dos castigos físicos, em que a palmatória era o instrumento mais usado para impor a disciplina e, quando necessário, também a aprendizagem. Para muitos pais, o Instituto fazia milagres com seus critérios. A formação moral e religiosa também era prioridade nessa escola, criada e dirigida por um vocacionado para o ministério religioso. Afinal, Pedro Reis pensara em ser padre, não tendo logrado seu intento porque as condições financeiras o impediram.

Mesmo não sendo oficialmente o diretor daquela escola, "toda a organização e iniciativas partiam do professor Pedro Reis" conta o professor 
Manoel, que ainda vive, em entrevista para elaboração desse trabalho, A forma como era conduzida a escola e como se dava o ensino no Instituto atraía muitos alunos de outros municípios e, por isso, foi criado o regime de internato que funcionou de 1944 até 1965. Os internos, todos do sexo masculino, vindos de cidades vizinhas, moravam na residência do Diretor da escola e freqüentavam as aulas normalmente. Nos finais de semana podiam passar com a família, caso conseguissem boas notas de aproveitamento e comportamento. Do contrário, permaneciam aos sábados e domingos fazendo "banca", o que significava estudos isolados e obrigatórios. Quando o professor Pedro Reis decidiu acabar com o regime de internato, um dos professores do Instituto resolveu acolher esses alunos em sua residência por mais alguns anos, até 1965, quando já era pequeno o número de internos. Os meios de transportes tinham evoluído e as rodovias passaram a ligar as cidades da região a Arapiraca, tornando fácil o seu acesso diário, o que, inclusive, tornaria a cidade um pólo regional de atração graças ao seu desenvolvimento econômico. Dessa forma, aqueles que residiam em cidades próximas podiam se deslocar todos os dias para chegar no horário certo ao Instituto.

A disciplina era rigorosa, começando pelo uso obrigatório do fardamento: para os meninos, exigiam-se calça e camisa cáqui e gravata com detalhe em azul, enquanto para as meninas era obrigatório o uso de blusa branca de mangas compridas e saia grená, de pregas; meias brancas e sapatos pretos, completavam o uniforme.. O som de uma campainha obrigava os alunos a entrarem em fila para ocupar seus lugares na sala de aula, sair e voltar nos intervalos e, finalmente, deixar a escola no término do turno.

$\mathrm{Na}$ sala de aula, a leitura, a tabuada, o ditado eram usados como práticas prioritárias. O uso de caligrafia era freqüente em todas as séries. Em português, o aluno da terceira série devia conhecer o sujeito das orações e seus predicados, provando isso ao seu professor, para então ser aprovado para a série seguinte. A tabuada de multiplicar e dividir era decorada e respondida sem muito tempo para pensar. Aos sábados aconteciam "as sabatinas"; quem não respondesse corretamente ás perguntas, apanhava de palmatória e quem acertava as respostas tinha o direito de bater naquele que errou. 
Com o curso pré-primário, o primário e mais um curso de Datilografia criado no segundo ano de funcionamento, o Instituto preparava os alunos para se submeterem ao exame de admissão ao Ginásio. Concordando com essa prática, muitos ex-alunos do Instituto consideram de grande importância a formação recebida naquela instituição de ensino, a exemplo de J. P.N, que, numa entrevista concedida a José Maria de Vasconcelos, o qual analisava a trajetória do Instituto São Luís para elaborar um trabalho a ser apresentado ao Curso de Pós Graduação em Ciências Humanas da FUNESA, assim declarou:

\begin{abstract}
Passei a estudar no Instituto São Luís em 1955. Fiz naquele ano o terceiro ano primário. E que primário. Sob a batuta do professor Adalberto Ribeiro Lima, o maior mestre que conheci, aprendi a ler e escrever corretamente, análise lógica, as operações fundamentais, frações ordinárias e decimais, problemas de números inteiros e fracionários. Estava naquela altura preparado para a vida. Em 1957 prestei exame de admissão ao ginásio e com a segurança de um primário bem feito a aprovação foi tranqüila entre os primeiros.
\end{abstract}

Outra declaração de reconhecimento de excelência do ensino desenvolvido no Instituto foi a de J.E.S. em entrevista dada para elaboração desse trabalho:

No Instituto São Luís eu aprendi tudo que foi necessário para fazer um bom ginásio, pedagógico e até mesmo a faculdade. Lá eu aprendi a escrever corretamente, melhorei minha letra com o uso da caligrafia e na matemática não tenho inveja de nenhum matemático para desenvolver cálculos. Devo tudo isso ao Instituto.

Outra ex-aluna, S.V. testemunhou na defesa das ações tradicionais no Instituto São Luís afirmando que seus pais eram de acordo com as punições da escola para manter a disciplina ao mesmo tempo que disciplinava os jovens também fora da escola:"quando eu chegava em casa com as mãos vermelhas minha mãe já sabia e me dava mais castigos". Podemos dessa forma, destacar a prática pedagógica desenvolvida pelo professor Pedro Reis em Arapiraca, semelhante áquela desenvolvida pela professora D. Linda, como um elemento que serviu de alavanca para a cultura daquela população, promovendo principalmente para a juventude, mais oportunidades. 


\section{Considerações finais}

$\mathrm{Na}$ pesquisa realizada, percebemos que a prática pedagógica desenvolvida pelos professores investigados, o professor Pedro Reis e a professora D."Linda" foi de cunho tradicional, defendendo valores morais, éticos e cristãos, recebendo, portanto, influencia da Igreja; no entanto, foram também de muita importância para a construção daquela sociedade, contribuindo com a formação cultural e religiosa.

Entre semelhanças e diferenças, ambos apresentaram trabalho capaz de deixar fortes influências e contribuições para as novas gerações. A professora D. Linda é homenageada com o nome do Grupo Escolar construído em 2003 na localidade de Baixa Grande de Cima; a escola municipal que levava o nome do Dr. Raul Armando passou a se chamar Escola de Ensino Fundamental, Lindinalva Eulália de Farias. Já o professor Pedro Reis deu nome a uma escola pública estadual e continua na memória da educação arapiraquense como um grande colaborador. Apesar das diferenças na formação inicial, na estrutura dos ambientes escolares e no perfil dos alunos, evidenciamos que os dois professores que tiveram sua prática analisada para elaboração desse texto, contribuíram de forma decisiva na formação da sociedade do município arapiraquense.

\section{Referências bibliográficas}

1. ALMEIDA, Leda Maria. Rupturas e Permanências em Alagoas: 017 de julho de 1997 em questão. Maceió: Catavento,1999

2. COSTA, Craveiro. Instrução pública e Instituições Culturais de Alagoas.In: VERÇOSA, Elcio de Gusmão (org) Caminhos da Educação: da colônia aos dias atuais. Maceió/São Paulo: Catavento, 2001

3. FAORO, Raymundo. (1925) Os Donos do Poder: formação do patrono político brasileiro. (v. 1 e 2) São Paulo: Globo, 2000.

4. FARIAS, Maria Aparecida de. O Romper Silêncio: a trajetória da educação em Arapiraca até á década de 1950. Dissertação do Mestrado em Educação Brasileira, 2007.

5. GUEDES, Zezito. Arapiraca através do Tempo. Maceió: Gráfica Montergraphy Ltda, 1999.

6. HUNT, K. J. \& SHERMAN, Howard J. História do Pensamento Econômico. Petrópolis: Vozes, 1994. 
7. MACEDO, Valdemar de Oliveira. Raízes e Futuros de Arapiraca. Maceió-AL. Ed. Gazeta de Alagoas, 1992.

8. MACEDO, Valdemar de Oliveira. Raízes e Futuros de Arapiraca. Maceió-AL: Ed. Gazeta de Alagoas, 1992.

9. MARTINS, J. S. O Poder e o Atraso: Ensaios de Sociologia da História Lenta. São Paulo: Hucitec, 1994.

10. RAMOS, Graciliano. Alguns números relativos á instrução primária em Alagoas. In. VERÇOSA, Elcio de Gusmão. (org.) Caminhos da Educação em Alagoas: da colônia aos dias atuais. Maceió, São Paulo: Ed. Catavento, 2001.

11. VERÇOSA, Elcio de Gusmão. Cultura e Educação nas Alagoas: História, Histórias. Maceió: EDUFAL, 1997,

12. WEBER, M.A. A Ética Protestante.O Espirito do Capitalismo. São Paulo: Martin Claret, 2005. 